\title{
Asthma Control and Its Predictive Factors in Adult Asthma Patients
}

\author{
Eman Albataineh ${ }^{\mathrm{a}, \mathrm{g}}$, Enas Al-Zayadneh ${ }^{\mathrm{b}}$, Hani Al-Shagahin ${ }^{\mathrm{c}}$, \\ Ahlam AL Soloman ${ }^{\mathrm{d}}$, Areej Altarawneh ${ }^{\mathrm{e}}$, Ibrahim Aldmour ${ }^{\mathrm{f}}$
}

\begin{abstract}
Background: Asthma is a highly prevalent condition that remains difficult to control, as its associated factors remain poorly understood. Thus, the primary aim of the present investigation was to determine the prevalence of uncontrolled asthma in hospital units in south Jordan and to evaluate the risk factors that may contribute to uncontrolled asthma.

Methods: This was a cross-sectional study involving 93 patients aged $40.5 \pm 13.6$ years that met the criteria of the Global Initiative for Asthma (GINA). Relevant patient data were collected via a questionnaire and through a review of medical records. The questionnaire comprised of sections pertaining to sociodemographic and clinical characteristics, as well as pharmacological asthma treatment, asthma severity and asthma control. Asthma severity was determined in line with the GINA guidelines, whereby the patients were classified into four groups (intermittent, mild persistent, moderate persistent or severe persistent). Moreover, based on the findings yielded by the asthma control questionnaire (ACQ), patients were divided into three levels, whereby those diagnosed with partly controlled and uncontrolled asthma were combined into one group, denoted as "poorly controlled asthma", with "uncontrolled asthma" and "controlled asthma" as the remaining two groups. Atopy was defined as one or more positive reactions $(\mathrm{A} / \mathrm{H}$ ratio $>1)$ on a skin prick test.
\end{abstract}

Results: Asthma control was achieved in $45.2 \%$ of the sample. Moreover, older age, severe asthma according to the GINA guidelines, longer duration of asthma, atopy, being on treatment for asthma

Manuscript submitted October 9, 2019, accepted October 30, 2019

aDepartment of Microbiology and Immunology, Faculty of Medicine, Mutah University, Al-Karak, Jordan

bepartment of Pediatrics, Faculty of Medicine, Mutah University, Al-Karak, Jordan

'Department of Special Surgery, Faculty of Medicine, Mutah University, AlKarak, Jordan

dPrince Ali Bin Al Hussein Hospital, Al-Karak, Jordan

eAlbasheer Hospital, Amman, Jordan

${ }_{\mathrm{f}}^{\mathrm{A}} \mathrm{l}-\mathrm{Karak}$ Governmental Hospital, Al-Karak, Jordan

'Corresponding Author: Eman Albataineh, Department of Microbiology and Immunology, Faculty of Medicine, Mutah University, Al-Karak, Jordan. Email: emanbatayneh@yahoo.com

doi: https://doi.org/10.14740/jocmr4021 and history of allergic rhinitis were identified as the main risk factors contributing to poorly controlled asthma. Multivariate analyses, however, revealed that only atopy to two or more allergens and having severe asthmatic attacks were statistically significantly associated with poorly controlled asthma, for which the odds ratio Mantel-Haenszel (ORMH) of 17.2 and 2.2 was obtained, respectively.

Conclusion: Our findings indicate that severe asthma and atopy to two or more allergens are the main risk factors for uncontrolled asthma. However, further studies with larger sample sizes are needed to confirm these results.

Keywords: Asthma control; Atopy; Asthma severity

\section{Introduction}

Asthma continues to be a major public health concern worldwide [1], as it presently affects more than 300 million individuals, generating a substantial burden for both patients and the healthcare system [2]. Yet, despite its socioeconomic significance, asthma prevalence trends among adults for the preceding decade, as well as data on allergic asthma and non-allergic asthma as separate conditions, are lacking.

Nonetheless, Backman reported an increase in the prevalence of allergic asthma from 5\% in 1996 to $7.3 \%$ in 2016 , while noting minimal changes in the prevalence of non-allergic asthma (3.4-3.8\%) in the same period [3]. According to a recent Jordanian study, in 2018, asthma was diagnosed in $6.2 \%$ adolescents in northern Jordan [4].

Genetic [5], developmental and environmental factors, such as viral infections [6] and occupational exposure [7], have been associated with asthma susceptibility, age at onset and severity. Although disease pathogenesis has not been fully elucidated, development of an immune response to allergens is recognized as a major risk factor [8].

The Global Initiative for Asthma (GINA) guidelines provide two asthma classification systems [9], based respectively on severity (intermittent, mild persistent, moderate persistent or severe persistent) and on asthma control level (controlled, partly controlled or uncontrolled) [9]. The latter, more recent, classification is preferred in clinical practice.

Although asthma control can be assessed via a variety of validated questionnaires, asthma control questionnaire (ACQ) 
Juniper is most widely used. Its longer form takes into account day and night symptoms and a $\beta_{2}$-agonist as needed, as well as the baseline airway caliber measured by forced expiratory volume in $1 \mathrm{~s}$ (FEV1) [10]. Several shortened versions are also in use, in which either the FEV1 item and/or the $\beta_{2}$-agonist consumption item are omitted, as they have been shown to provide similar information on the level of asthma control achieved by treatment [11].

However, in spite of these new guidelines, according to population studies conducted in the past decade, asthma control remains elusive for the majority of patients [12], even though mild to moderate asthma is the most prevalent and should respond to modern therapeutic regimens [13]. Findings yielded by the asthma control and treatment (REACT) study focusing on US patients with moderate to severe asthma receiving standard asthma medications noted that $55 \%$ of the sample failed to achieve asthma control [12]. This is a serious issue, as uncontrolled asthma can lead to morbidity, while reducing professional achievement potential [14] and increasing medical resource expenditure [15]. Therefore, it is important to understand the risk factors for uncontrolled asthma.

The level of asthma control and its relationship with asthma severity and atopy is complex and the importance of the intensity of allergic sensitization to asthma severity is presently poorly understood. However, most extant studies examining these issues focused on children and yielded inclusive findings. Thus, in the present cross-sectional study, the sample comprises of a cohort of adult asthma patients recruited from the respiratory clinic in Prince Ali Military Hospital, Al-Karak. The primary aim of this study was to elucidate the degree of asthma control in Jordanian adult patients and to evaluate atopy, asthma severity and other risk factors associated with poorly controlled asthma in this cohort.

\section{Materials and Methods}

\section{Data collection}

The present study was approved by the Ethics and Scientific Committees of the Faculty of Medicine at Mutah University prior to administering the self-completed questionnaires. The study was performed during 2012 - 2013 on patients attending asthma clinic without excluding those who were already receiving inhaled corticosteroid treatment, current smokers or those experiencing an asthma exacerbation at the time of the investigation. Thus, the study sample included newly diagnosed asthmatics, as well as patients with a well-established diagnosis whose disease duration was variable.

\section{Patient characteristics}

Information on sex, age, body mass index (BMI), educational attainment, asthma duration, current medication and symptoms was collected from all patients, and personal and family history of allergy, personal history of any other co-morbid diseases, including hypertension, heart disease and diabetes were collected under the name of history of any ongoing chronic disease. Smoking history and history of influenza vaccination were also obtained. Atopy was defined as having a positive skin prick test (SPT).

\section{Assessment of asthma control and severity}

All patients that agreed to take part in the study were administered a five-item questionnaire assessing their asthma symptoms, use of rescue medications and the impact of asthma on daily life [16]. They were also administered an asthma control test, whereby a score of $\geq 25,20-24,16-19$ and $\leq 15$ points indicated full control, control, partial control and uncontrolled disease, respectively. However, for statistical analyses, only two groups were formed, respectively comprising of patients that scored above and below 20 points. This threshold was chosen as the ACT score $<20$ was confirmed in previous studies as a useful threshold for identifying patients with poorly controlled asthma, as defined by GINA [17].

According to the GINA criteria [18], spirometry test results, asthma symptoms and medication use (especially doses of inhaled corticosteroids) are typically used in clinical practice to classify patients into four groups according to asthma severity (intermittent, mild persistent, moderate persistent or severe persistent).

\section{Allergy skin tests}

Once the informed consent was obtained from patients that agreed to partake in the study, they were subjected to the SPT, which included all common inhalant allergens, namely Dermatophagoides pteronyssinus $(D p)$ and Dermatophagoides farinae (Df) house dust mite (HDM), olive pollen, cat dander, dog dander, compositae, wall pellitory, salsola kali, four cereals, 12 grasses and mold, along with positive control (histamine) and negative control (vehicle) (Stallergenes, France), in accordance with published guidelines [19]. Atopy was defined as having an allergen-induced wheal reaction equal to or greater than that caused by histamine $(1 \mathrm{mg} / \mathrm{mL})$ or exceeding $3 \mathrm{~mm}$ in diameter.

\section{Statistical analyses}

As the data were not normally distributed, based on the findings of the Kolmogorov-Smirnov test $(\mathrm{P}<0.05)$, non-parametric analysis was performed using Mann-Whitney U test, and mean and standard errors were also calculated. Categorical variables were analyzed using the Chi-squared test. However, Fisher's exact test was performed when $>20 \%$ of the expected frequencies were below 6. Multi-logistic regressions were conducted to calculate adjusted odds ratio (AOR) and $95 \%$ confidence intervals ( $95 \%$ CIs) to assess the relationship between risk factors and uncontrolled disease, including the potential confounders. A P-value below 0.05 was considered statistically significant. In these analyses, patients with partly 
controlled and uncontrolled asthma were combined into one group denoted as "poorly controlled asthma". Independent variables that were statistically significantly associated with asthma control in the univariate analyses were included in the multivariate analyses. All the analyses were performed using SPSS software version 16.0 (SPSS Inc., Chicago, IL, USA).

\section{Results}

\section{Sample characteristics}

The study sample comprised of 93 asthmatic adults aged 40.5 $\pm 13.6,36.6 \%$ of whom were male and $63.4 \%$ were female. The average amount of time patients had suffered from asthma was $7.3 \pm 7.9$ years and the average mean BMI was $27.6 \pm$ 5.0. Allergy SPT was positive in $54(58.1 \%)$ cases. Although $72(77.4 \%)$ patients were receiving asthma treatment, asthma control was achieved in only $45.2 \%$ of the sample. Moreover, $66.7 \%, 49.5 \%, 5.4 \%, 25.8 \%$ and $28 \%$ of the patients self-reported allergic rhinitis (hay fever), allergic conjunctivitis, food allergy, atopic dermatitis and chronic disease including any of hypertension, heart disease or diabetes, respectively. The history of smoking and influenza vaccination was reported by $72 \%$ and $70 \%$ of the sample, respectively. GINA classification of asthma severity is summarized in Table 1, indicating that in Jordan asthma is most commonly treated using inhaled $\beta_{2}$-agonist, followed by inhaled corticosteroids and lastly oral $\beta_{2}$-agonist.

\section{Characteristics of patients with controlled, partially con- trolled and uncontrolled asthma}

As previously explained, patients with partly controlled and uncontrolled asthma were combined into the "poorly controlled asthma" group. In the age group $\geq 55$ years, all patients had uncontrolled asthma, while this was the case for only $37.7 \%$ of those aged $<55$ years $(\mathrm{P}=0.0)$, as shown in Table 2 . Asthma duration in the "uncontrolled" and "controlled" group was 8.8 and 5.4 years, respectively, and the difference was statistically significant at $\mathrm{P}$ of 0.037 (data not shown). Being atopic to one or more allergens was statistically significantly associated with uncontrolled asthma. Moreover, having allergic rhinitis alongside asthma was related to a greater likelihood of poor asthma control (Table 3 ). The proportion of patients who were on treatment for asthma were significantly higher in the uncontrolled asthma than controlled asthma groups $(\mathrm{P}=0.02)$.

\section{GINA-based asthma severity in patients with controlled and uncontrolled asthma}

Based on the GINA classification of asthma severity, $30.1 \%$ of the asthma patients included in the study had intermittent asthma, $43.0 \%$ had mild persistent asthma, $21.5 \%$ had moderate persistent asthma and $5.4 \%$ had severe persistent asthma. According to the asthma control test, uncontrolled asthma was noted in $22.6 \%, 20.4 \%$ and $3.2 \%$ of mild persistent, moderate persistent and severe persistent, respectively (Fig. 1, Table 3). Moreover, control was achieved in $71.4 \%$ of patients diagnosed with intermittent asthma, whereby the association between asthma severity and absence of control was statistically significant $\left(\chi^{2}=20.97 ; \mathrm{P}<0.05\right)$, as shown in Table 3 .

\section{Frequency of positive SPTs by aeroallergen type}

The SPT was positive to one or more allergens in $54(58.1 \%)$ cases. In these patients, the most common offending allergen was olive pollen, followed by HDM and cat dander (Fig. 2). Moreover, allergic sensitization was noted in $45.2 \%$ of the uncontrolled group, which was significantly higher than $12.9 \%$ noted for the controlled group (Table 2). Uncontrolled asthma was statistically significantly associated with cat dander, salsola kali, $D f$, cereals, olive pollens and grasses $(\mathrm{P}<0.05)$ (Fig. 2).

\section{Comorbid allergic disease and other chronic diseases}

Comorbid conditions noted in our patient cohort included allergic rhinitis (66.7\%), allergic conjunctivitis (49.5), food allergy (5.4\%), eczema (25.8\%) and other chronic diseases such as hypertension, diabetes and heart diseases $(28 \%)$. Patients with poorly controlled asthma were significantly more likely to suffer from allergic rhinitis than were those whose asthma was well controlled $(\mathrm{P}=0.015)$, as shown in Table 2 .

\section{Pharmacological treatments utilized by the asthmatic pa- tients}

In the uncontrolled asthma group, the proportions of patients who used inhaled corticosteroids (ICS), long-acting inhaled $\beta_{2}$-agonist (LABA) and/or oral short-acting $\beta_{2}$-agonist were non-significantly higher than in the controlled asthma group (Fig. 3). Moreover, while some patients received more than one treatment, inhaled LABAs were most commonly prescribed pharmacological treatment, followed by ICSs and oral $\beta_{2}$-agonist.

Furthermore, no SPT suppression was achieved with the drugs patients were taking, as the percentage of patients receiving ICS who had positive and negative allergy test was the same $(\mathrm{P}>0.05)($ Table 4$)$.

\section{Risk factors for uncontrolled asthma}

Univariate analysis revealed that age above 55 years, presence of allergic rhinitis, presence of atopy or atopy to two or more allergens, severe asthma according to the GINA guidelines, long duration of asthma disease and being on treatment were the main risk factors associated with uncontrolled asthma. Subsequent multiple logistic regression (MLR), after adjusting for the aforementioned confounding variables, showed that asthma severity $(\mathrm{P}=0.047)$ and atopy to two or more allergens 
Table 1. Characteristics of the Study Population

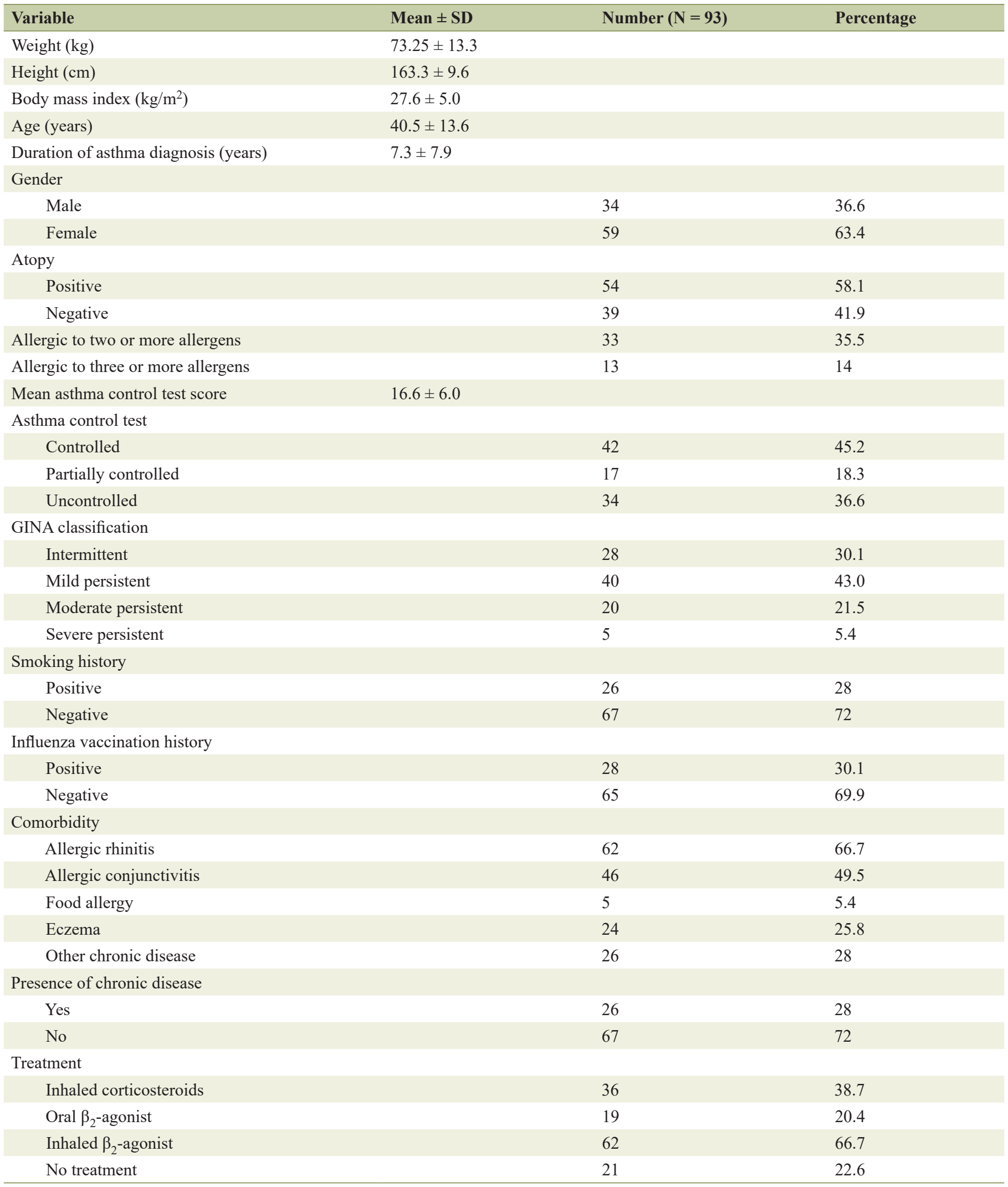

GINA: Global Initiative for Asthma; SD: standard deviation. 
Table 2. Baseline Characteristics of the Overall Sample for Controlled, Partly Controlled and Uncontrolled Asthma

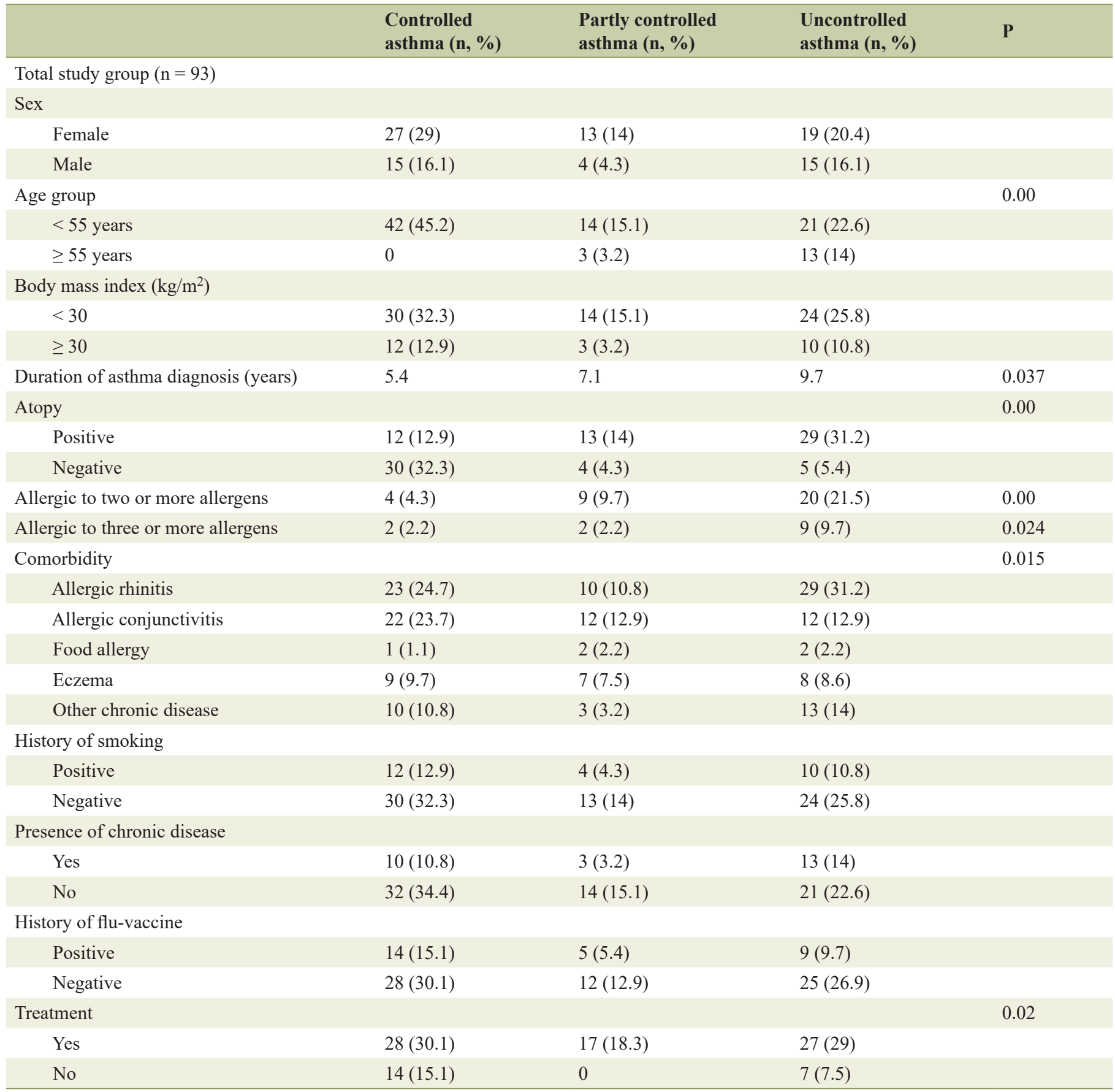

Absolute number and percentage in brackets.

$(\mathrm{P}=0.00)$ were the only factors that were statically significantly related to uncontrolled asthma, for which the ORMH of 17.2 and 2.2 was obtained, respectively (Table 5).

\section{Discussion}

Low levels of asthma control are reported in many countries worldwide [12].

Moreover, only $30 \%$ of the adult patients that took part in a recent Jordanian study were reported to have achieved asthma control [20]. A study from northern of Jordan showed that smoking is the main cause of poor asthma control in adolescent[4] and two studies from Jordan attributed poor control to non-adherence or improper use of inhalers [21, 22]; moreover one study showed a significant association between the level of 
Table 3. Frequency of GINA-Based Asthma Severity Cases in the Controlled and Uncontrolled Asthma Groups

\begin{tabular}{llll}
\hline \multirow{2}{*}{ GINA } & \multicolumn{2}{c}{ Asthma control test } & Chi-squared \\
\cline { 2 - 4 } & Controlled $(\mathbf{n}, \boldsymbol{\%})$ & Uncontrolled (n, \%) & 20.97 \\
\hline Intermittent & $20(21.5 \%)$ & $8(8.6 \%)$ & 0.00 \\
Mild persistent & $19(20.4 \%)$ & $21(22.6 \%)$ & \\
Moderate persistent & $1(1.1 \%)$ & $19(20.4 \%)$ \\
Severe persistent & $2(2.2 \%)$ & $3(3.2 \%)$ \\
\hline
\end{tabular}

Absolute number and percentage in brackets. GINA: Global Initiative for Asthma.

asthma control and genetic in Arab population [23]. However, this issue is rarely investigated in the south of Jordan and the burden of uncontrolled asthma on patients is largely unknown.

A large-scale cross-sectional epidemiological study conducted by EMSA (Assessment of Asthma Control in Adult Asthma Population in the Middle East and North Africa) in 2018 revealed that less than one-third of asthma patients achieved adequate control, which was attributed to poor mediation adherence, active smoking, absence of medical insurance, lower level of education, or long disease duration prior to seeking treatment [24]. These findings indicate that treatment access and medication adherence, along with better followup and education among healthcare providers and patients is needed to achieve greater asthma control. In the USA, on the other hand, female sex, low educational attainment, inadequate household income and certain comorbidities (such as sinusitis) emerged as the most relevant predictive factors of uncontrolled asthma [12].

The results yielded by the present study suggest that, in Jordan, older age ( $>55$ years), atopy to two or more allergens, comorbid allergic rhinitis, being on treatment and asthma duration are the most significant factors contributing to the likelihood of uncontrolled asthma.

These findings are highly relevant, as elderly patients tend to have concomitant diseases and are therefore prescribed a wide range of medications, which leads to an increased risk of reduced treatment adherence [25]. Aging is also associated with a decline in immune defenses [26]. Elderly individuals might also have lower expectations about the degree of control that can be achieved [27]. Interestingly, it has also been reported that the response to $\beta_{2}$-agonists declines with age due to a decreased number of $\beta_{2}$-receptors in smooth muscle tissue

\section{The relationship between asthma severity according to Global Initiative for Asthma and asthma control test score}

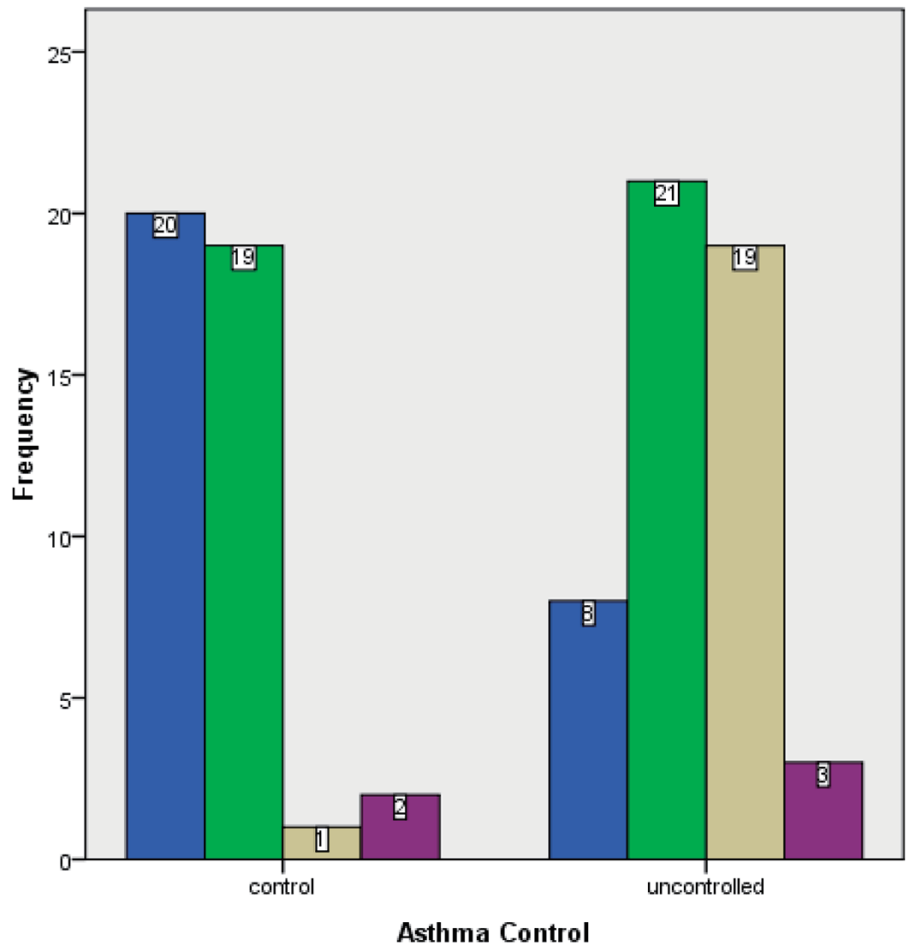

GINA

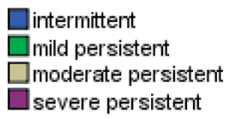

moderate persistent
severe persistent

Figure 1. Frequency of GINA-based asthma severity cases in the controlled and uncontrolled asthma groups. GINA: Global Initiative for Asthma. 
The relationship between type of allergen and asthma control
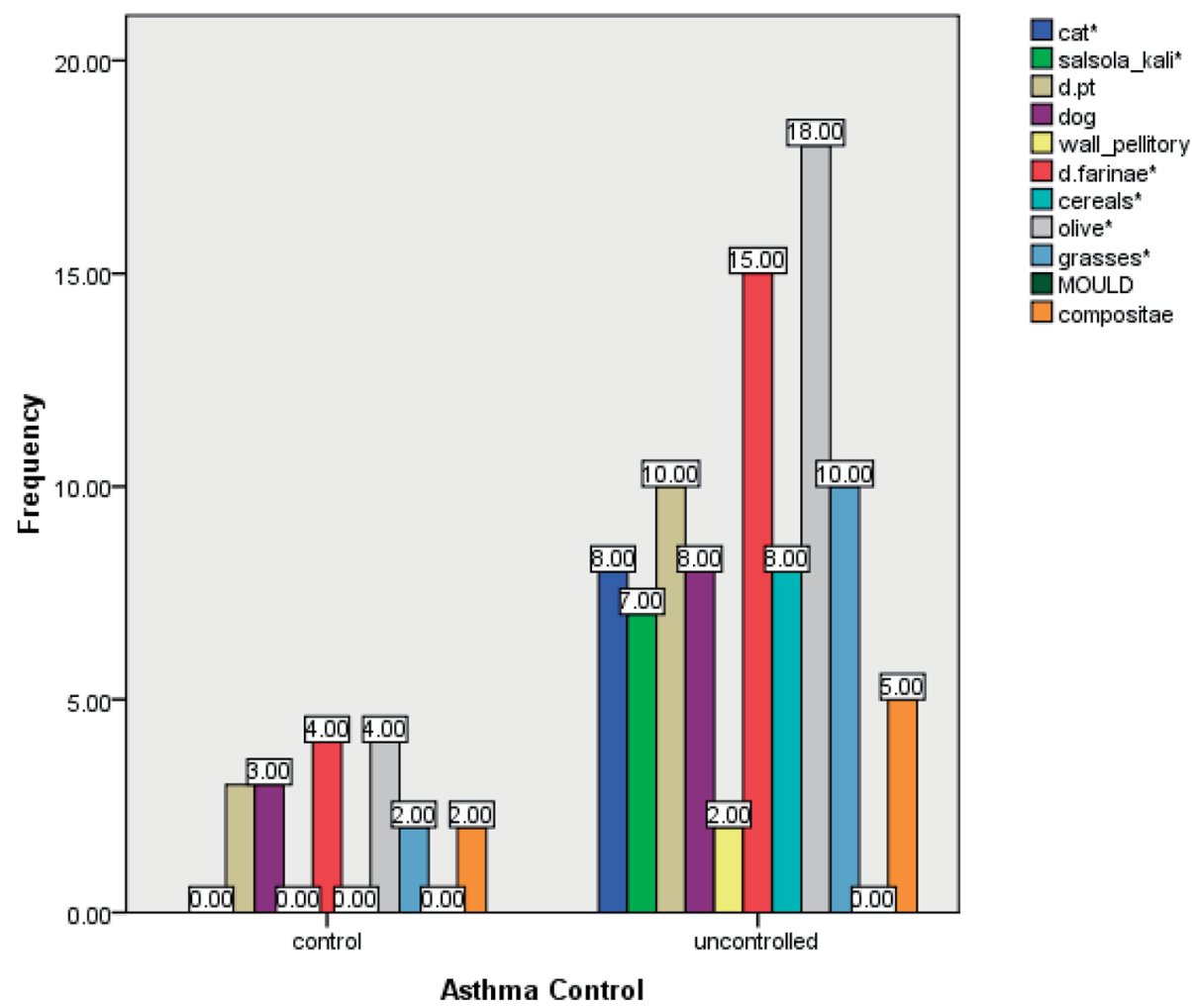

Figure 2. The frequency of aero-allergen sensitivity in controlled and uncontrolled asthma groups.

[28].

Yet despite the growing recognition of atopy as a risk factor for the development of asthma, its association with uncontrolled asthma in adults remains poorly understood [29].

Authors that have conducted cluster analysis of asthma phenotypes tend to concur that various clusters of patients with atopy are quite heterogeneous in terms of symptom severity, pulmonary function and tendency for exacerbations. However, Kampe identified being female and having early childhood onset asthma as the main risk factors for severe adult asthma [30].

Furthermore, Jaakkola and co-workers [31] found that atopy is a strong determinant of asthma in adulthood, suggesting that atopy reduction could significantly reduce the prevalence of adult asthma. Nonetheless, the link between the intensity of allergic sensitization and asthma severity remains unclear. Peat and colleagues [32] found linear relationships between dust mite wheal size and asthma severity. Sarpong and colleagues [33] similarly found a positive association between number of positive SPTs and asthma severity evaluated by $\mathrm{FEV}_{1}$ and medication usage. On the other hand, asthma severity was relatively similar in skin test-negative and skin testpositive groups [34].

Findings yielded by the present study indicate that sensitivity to two or more aero-allergens is a risk factor for the development of uncontrolled asthma, supporting the previously published results [35]. The specific allergens that were found to be significantly associated with uncontrolled asthma in Jor- danian patients were cat dander, salsola kali, $D f$, cereals, olive pollens and grasses. As these results are also supported by available evidence, environmental allergen avoidance is likely to alleviate some of the asthma symptoms [36, 37]. However, further investigations are needed to ascertain whether practical avoidance measures are sufficient to achieve improvement in asthma control.

Although it is possible that skin test responses were suppressed by high doses of corticosteroids (oral or inhaled) in our patient cohort, no association between lack of skin test responses and treatment with oral corticosteroids (OCSs) was noted. In extant studies, skin test responses were noted in many cases despite chronic administration of OCSs [38].

Several studies demonstrated that allergic rhinitis is a risk factor for poorer asthma control and more severe asthma symptoms [39]. For example, $>50 \%$ of adult patients with asthma that took part in the REACT study experienced hay fever and allergic rhinitis [40]. Moreover, Cazzola et al [41] reported that allergic rhinitis was the most frequent comorbid condition suffered by Italian adults with asthma, affecting 19.7\% individuals, whereas a much higher prevalence $(60-80 \%)$ was noted in Korea [42], where this condition was also closely associated with more frequent asthma attacks, emergency room visits and poor asthma control [43].

Longer asthma duration is frequently linked with poor disease control due to irreversible airflow obstruction. Asthma is a chronic disease with diverse clinical manifestations that fa- 


\section{Pharmacological treatments in both controlled and uncontrolled asthmatic patients}

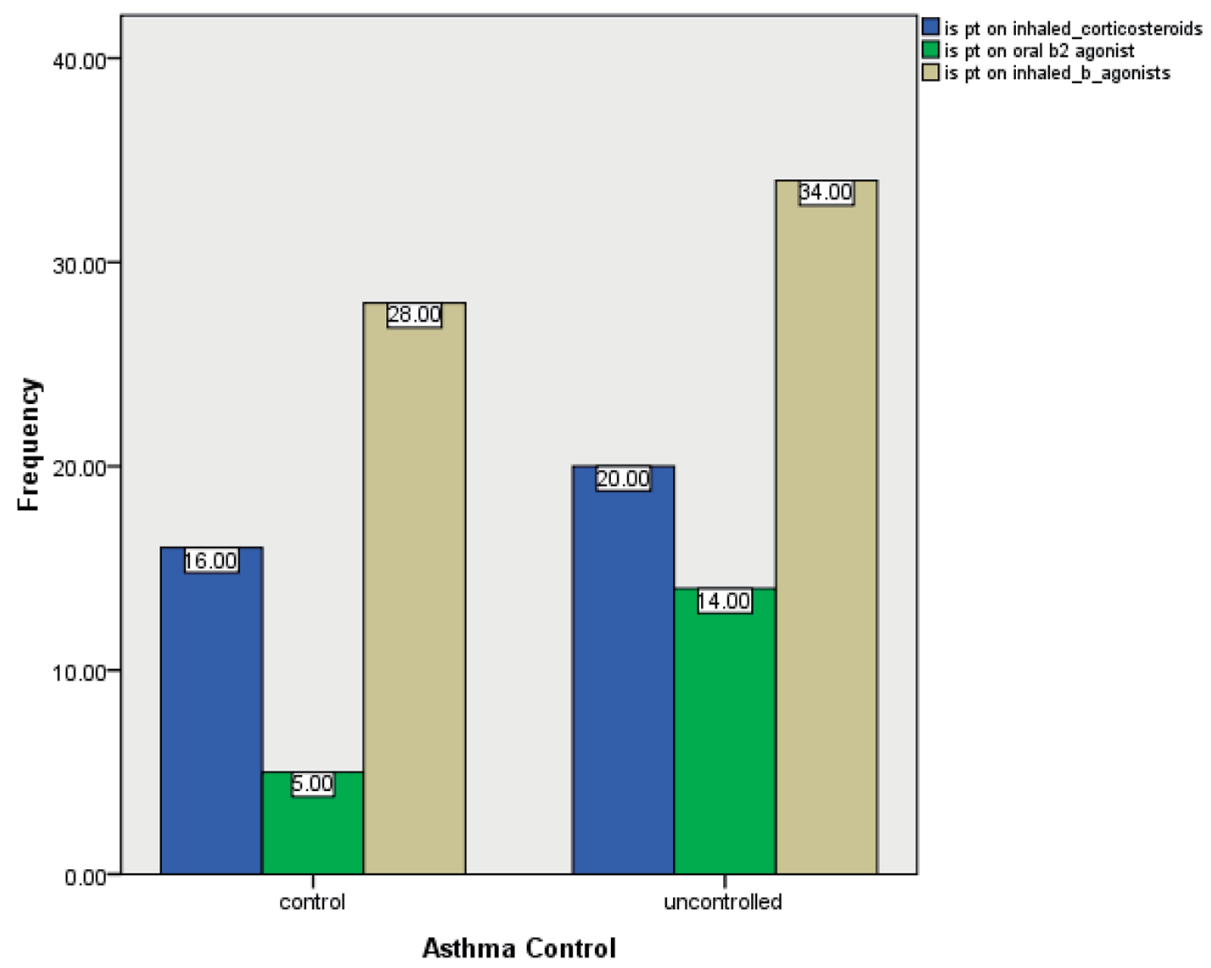

Figure 3. Asthma treatment with inhaled corticosteroids, inhaled $\beta_{2}$-agonist and oral $\beta_{2}$-agonist in the controlled and uncontrolled asthma groups.

vor T helper type 2 (TH2) response, whereby interleukins lead to the formation of immunoglobulin (Ig) E, pro-inflammatory cytokines and bronchial hyper-reactivity [44]. T cells, derived cytokines, IgE and mast cells initiate early asthmatic reaction and recruitment, whereby eosinophil activation was posited to play a role in the persistent asthma phenotype characterized by chronic airflow obstruction [45], which becomes irreversible after living with the disease for a long time.

In several extant studies, moderate level of agreement between ACT and GINA asthma control classifications was obtained [46]. In contrast, in the present study, this association was significant. Discrepancies between the ACT classification and GINA classification of asthma control noted in some earlier studies could be explained by variability in item content and grading between the ACT and GINA definitions [17].

Poor adherence is a recognized risk factor for poor asthma control [47]. Although in the present study, the proportion of patients who used inhaled corticosteroids (ICS), long-acting inhaled $\beta_{2}$-agonist (LABA) and/or oral short-acting $\beta_{2}$-agonist were non-significantly higher in the uncontrolled asthma than in the controlled asthma group, being on treatment has a significant association with uncontrolled asthma. Moreover, in

Table 4. Frequency of Positive Allergy Tests for Patients Taking and Not Taking Inhaled Corticosteroids

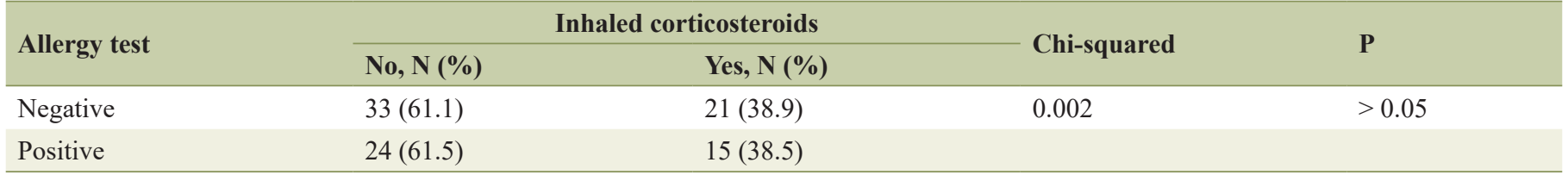

Absolute number and percentage in brackets.

Table 5. Factors Associated With Uncontrolled Asthma Obtained via MLR Analysis

\begin{tabular}{lllll}
\hline Variable & Adjusted OR & $\mathbf{9 5 \%}$ CI (OR) & $\boldsymbol{\chi}^{\mathbf{2} \text { Stat. (df) }}$ & P \\
\hline GINA & 2.2 & $1.011-4.714$ & 4.0 & 0.047 \\
Allergy positive to two allergens or more & 17.2 & $4.301-68.702$ & 16.2 & 0.00 \\
\hline
\end{tabular}

MLR: multiple logistic regression; GINA: Global Initiative for Asthma; OR: odds ratio; Cl: confidence interval. 
our patient cohort, as common in low-income countries, shortacting $\beta_{2}$-agonist (SABA) was the most frequent form of treatment even though it has lower efficacy and safety [48].

Improved knowledge of asthma control and predictive factors is needed to address this major public healthcare burden in Jordan.

The present study findings confirm that, even in low-income countries, a simple assessment tool such as the ACT can be utilized to screen patients and categorize asthma control. This approach would facilitate a better treatment plan and is likely to contribute to greater asthma control. As absence of spirometer in many clinical settings is one of the barriers to asthma control assessment [49], it is essential to provide them in all health facilities. Nonetheless, if spirometer is not available, general practitioners in primary settings can use ACT. Despite the efficacy of such procedure, its effectiveness should be verified in actual primary health conditions to ensure comparable level of correlation among parameters.

\section{Acknowledgments}

The research team is thankful to all school directors and teachers who helped us in data collection.

\section{Financial Disclosure}

None to declare.

\section{Conflict of Interest}

The authors declare no conflict of interest.

\section{Informed Consent}

Written informed consent was obtained from all patients who participated in the present study, which was conducted in accordance with the Declaration of Helsinki.

\section{Author Contributions}

Ahlam AL Soloman, Areej Altarawneh and Ibrahim Aldmour performed research including data collection, and filled in data on the SPSS. Enas Al-Zayadneh and Hani Al-Shagahin performed research including patient recruitment, and provided expert clinical knowledge to revise critically. Eman Albataineh statistically analyzed the data, created tables and figures and wrote the paper, and designed research.

\section{References}

1. Pawankar R, Canonica GW, Holgate ST, Lockey RF. Allergic diseases and asthma: a major global health concern.
Curr Opin Allergy Clin Immunol. 2012;12(1):39-41.

2. To T, Stanojevic S, Moores G, Gershon AS, Bateman ED, Cruz AA, Boulet LP. Global asthma prevalence in adults: findings from the cross-sectional world health survey. BMC Public Health. 2012;12:204.

3. Backman H, Raisanen P, Hedman L, Stridsman C, Andersson M, Lindberg A, Lundback B, et al. Increased prevalence of allergic asthma from 1996 to 2006 and further to 2016-results from three population surveys. Clin Exp Allergy. 2017;47(11):1426-1435.

4. Al-Sheyab NA, Alomari MA. Prevalence, associated factors, and control level of asthma symptoms among adolescents in Northern Jordan. Int J Adolesc Med Health. 2018.

5. Cookson $\mathrm{W}$. The alliance of genes and environment in asthma and allergy. Nature. 1999;402(6760 Suppl):B5-11.

6. Halonen M, Stern DA, Lohman C, Wright AL, Brown MA, Martinez FD. Two subphenotypes of childhood asthma that differ in maternal and paternal influences on asthma risk. Am J Respir Crit Care Med. 1999;160(2):564-570.

7. Venables KM, Chan-Yeung M. Occupational asthma. Lancet. 1997;349(9063):1465-1469.

8. Platts-Mills TA. The role of immunoglobulin E in allergy and asthma. Am J Respir Crit Care Med. 2001;164(8 Pt 2):S1-5.

9. Health NIo. Global Initiative for Asthma. Global strategy for asthma management and prevention. NHLBI/WHO work shop report. 1995.

10. Juniper EF, O'Byrne PM, Guyatt GH, Ferrie PJ, King DR. Development and validation of a questionnaire to measure asthma control. Eur Respir J. 1999;14(4):902907.

11. Juniper EF, Svensson K, Mork AC, Stahl E. Measurement properties and interpretation of three shortened versions of the asthma control questionnaire. Respir Med. 2005;99(5):553-558.

12. Peters SP, Jones CA, Haselkorn T, Mink DR, Valacer DJ, Weiss ST. Real-world Evaluation of Asthma Control and Treatment (REACT): findings from a national Web-based survey. J Allergy Clin Immunol. 2007;119(6):14541461.

13. Carlstrom L, Castro M. Severe asthma: what makes it so hard to manage? Curr Allergy Asthma Rep. 2009;9(5):393-400.

14. O'Byrne PM, Pedersen S, Schatz M, Thoren A, Ekholm E, Carlsson LG, Busse WW. The poorly explored impact of uncontrolled asthma. Chest. 2013;143(2):511-523.

15. Accordini S, Corsico AG, Braggion M, Gerbase MW, Gislason D, Gulsvik A, Heinrich J, et al. The cost of persistent asthma in Europe: an international population-based study in adults. Int Arch Allergy Immunol. 2013;160(1):93-101.

16. Argus MV, Matthews EK. Stratigraphic excavation techniques for paleontologists. Journal of Paleontology. 1991;17:119-127.

17. Thomas M, Kay S, Pike J, Williams A, Rosenzweig JR, Hillyer EV, Price D. The Asthma Control Test (ACT) as a predictor of GINA guideline-defined asthma control: analysis of a multinational cross-sectional survey. Prim 
Care Respir J. 2009;18(1):41-49.

18. Health UDo, Services H. National heart, lung and blood institute, national asthma education and prevention program. Expert Panel Report 3: guidelines for the diagnosis and management of asthma. 2009.

19. Dreborg S, Frew A. Position paper: Allergen standardization and skin tests. Allergy. 1993;48(14 Suppl):49-54.

20. Almomani BA, Al-Sawalha NA, Samrah SM, Gamble JM, Al Momani MA. Asthma insights from Jordan: crosssectional observational study. J Asthma. 2016;53(4):349355.

21. Basheti IA, Obeidat NM, Reddel HK. Inhaler technique education and asthma control among patients hospitalized for asthma in Jordan. Saudi Pharm J. 2018;26(8):11271136.

22. Basheti IA, Salhi YB, Basheti MM, Hamadi SA, Al-Qerem W. Role of the pharmacist in improving inhaler technique and asthma management in rural areas in Jordan. Clin Pharmacol. 2019;11:103-116.

23. Almomani BA, Al-Eitan LN, Al-Sawalha NA, Samrah SM, Al-Quasmi MN. Association of genetic variants with level of asthma control in the Arab population. J Asthma Allergy. 2019;12:35-42.

24. Tarraf H, Al-Jahdali H, Al Qaseer AH, Gjurovic A, Haouichat $\mathrm{H}$, Khassawneh B, Mahboub B, et al. Asthma control in adults in the Middle East and North Africa: Results from the ESMAA study. Respir Med. 2018;138:64-73.

25. Melani AS. Management of asthma in the elderly patient. Clin Interv Aging. 2013;8:913-922.

26. Agarwal S, Busse PJ. Innate and adaptive immunosenescence. Ann Allergy Asthma Immunol. 2010;104(3):183190; quiz 190-182, 210.

27. Slavin RG, Haselkorn T, Lee JH, Zheng B, Deniz Y, Wenzel SE, TENOR Study Group. Asthma in older adults: observations from the epidemiology and natural history of asthma: outcomes and treatment regimens (TENOR) study. Ann Allergy Asthma Immunol. 2006;96(3):406414.

28. Connolly MJ, Crowley JJ, Charan NB, Nielson CP, Vestal RE. Impaired bronchodilator response to albuterol in healthy elderly men and women. Chest. 1995;108(2):401406.

29. Holt PG, Sly PD. Interaction between adaptive and innate immune pathways in the pathogenesis of atopic asthma: operation of a lung/bone marrow axis. Chest. 2011;139(5):1165-1171.

30. Kampe M, Lisspers K, Stallberg B, Sundh J, Montgomery $\mathrm{S}$, Janson C. Determinants of uncontrolled asthma in a Swedish asthma population: cross-sectional observational study. Eur Clin Respir J. 2014;1(1):24109.

31. Jaakkola MS, Ieromnimon A, Jaakkola JJ. Are atopy and specific IgE to mites and molds important for adult asthma? J Allergy Clin Immunol. 2006;117(3):642-648.

32. Peat JK, Tovey E, Gray EJ, Mellis CM, Woolcock AJ. Asthma severity and morbidity in a population sample of Sydney schoolchildren: Part II - Importance of house dust mite allergens. Aust N Z J Med. 1994;24(3):270-276.

33. Sarpong SB, Karrison T. Skin test reactivity to indoor allergens as a marker of asthma severity in children with asthma. Ann Allergy Asthma Immunol. 1998;80(4):303308.

34. Inouye T, Tarlo S, Broder I, Corey P, Davies G, Leznoff A, Mintz S, et al. Severity of asthma in skin test-negative and skin test-positive patients. J Allergy Clin Immunol. 1985;75(2):313-319.

35. Semik-Orzech A, Barczyk A, Pierzchala W. [The influence of sensitivity to fungal allergens on the development and course of allergic diseases of the respiratory tract]. Pneumonol Alergol Pol. 2008;76(1):29-36.

36. Bush RK. Indoor allergens, environmental avoidance, and allergic respiratory disease. Allergy Asthma Proc. 2008;29(6):575-579.

37. Eggleston PA. Improving indoor environments: reducing allergen exposures. J Allergy Clin Immunol. 2005;116(1):122-126.

38. Des Roches A, Paradis L, Bougeard YH, Godard P, Bousquet J, Chanez P. Long-term oral corticosteroid therapy does not alter the results of immediate-type allergy skin prick tests. J Allergy Clin Immunol. 1996;98(3):522-527.

39. Bousquet J, Khaltaev N, Cruz AA, Denburg J, Fokkens WJ, Togias A, Zuberbier T, et al. Allergic Rhinitis and its Impact on Asthma (ARIA) 2008 update (in collaboration with the World Health Organization, GA(2)LEN and AllerGen). Allergy. 2008;63(Suppl 86):8-160.

40. Haselkorn T, Chen H, Miller DP, Fish JE, Peters SP, Weiss ST, Jones CA. Asthma control and activity limitations: insights from the Real-world Evaluation of Asthma Control and Treatment (REACT) study. Ann Allergy Asthma Immunol. 2010;104(6):471-477.

41. Cazzola M, Calzetta L, Bettoncelli G, Novelli L, Cricelli C, Rogliani P. Asthma and comorbid medical illness. Eur Respir J. 2011;38(1):42-49.

42. Park HS, Choi GS, Cho JS, Kim YY. Epidemiology and current status of allergic rhinitis, asthma, and associated allergic diseases in Korea: ARIA Asia-Pacific workshop report. Asian Pac J Allergy Immunol. 2009;27(2-3):167171.

43. Bousquet J, Gaugris S, Kocevar VS, Zhang Q, Yin DD, Polos PG, Bjermer L. Increased risk of asthma attacks and emergency visits among asthma patients with allergic rhinitis: a subgroup analysis of the investigation of montelukast as a partner agent for complementary therapy [corrected]. Clin Exp Allergy. 2005;35(6):723-727.

44. Cengizlier MR, Misirlioglu ED. Evaluation of risk factors in patients diagnosed with bronchial asthma. Allergol Immunopathol (Madr). 2006;34(1):4-9.

45. Bumbacea D, Campbell D, Nguyen L, Carr D, Barnes PJ, Robinson D, Chung KF. Parameters associated with persistent airflow obstruction in chronic severe asthma. Eur Respir J. 2004;24(1):122-128.

46. Erkocoglu M, Akan A, Civelek E, Kan R, Azkur D, Kocabas CN. Consistency of GINA criteria and childhood asthma control test on the determination of asthma control. Pediatr Allergy Immunol. 2012;23(1):34-39.

47. Desalu OO, Fawibe AE, Salami AK. Assessment of the level of asthma control among adult patients in two tertiary care centers in Nigeria. J Asthma. 2012;49(7):765772. 
48. Chin MC, Sivasampu S, Khoo EM. Prescription of oral short-acting beta 2-agonist for asthma in non-resource poor settings: A national study in Malaysia. PLoS One. 2017;12(6):e0180443.
49. Schatz M, Mosen DM, Kosinski M, Vollmer WM, Magid DJ, O'Connor E, Zeiger RS. Validity of the Asthma Control Test completed at home. Am J Manag Care. 2007;13(12):661-667. 